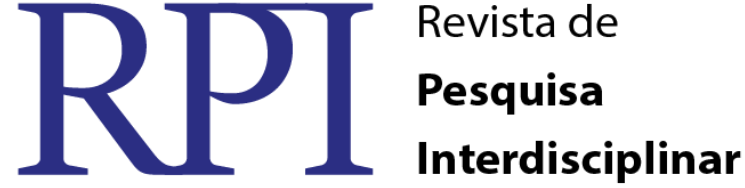

\section{CONTRIBUIÇÕES DO ESTÁGIO SUPERVISIONDADO NA FORMAÇÃO DISCENTE}

\author{
Danielly de Sousa Bezerra - UFCG ${ }^{1}$ \\ Edinardo Nogueira Costa - UFCG ${ }^{2}$ \\ Jefferson Antonio Marques - $\mathrm{UFCG}^{3}$
}

\begin{abstract}
RESUMO
O presente trabalho trata-se de uma pesquisa realizada por alunos do Curso de Licenciatura em Ciências Biológicas do Centro de Formação de Professores da Universidade Federal de Campina Grande - CFP/UFCG, na disciplina Estágio Supervisionado, com o objetivo de observar e analisar a importância do estágio na formação docente através da análise das ferramentas metodológicas adotadas pelas professoras, além dos possíveis recursos pedagógicos utilizados para trabalhar os conteúdos de Ciências Naturais. A pesquisa foi realizada em duas escolas da rede pública de ensino, sendo uma Estadual e outra Municipal, localizadas nos municípios de São João do Rio do Peixe e Cajazeiras, respectivamente, na Paraíba, em maio de 2016. A reflexão da ação e prática pedagógica são instrumentos essenciais para a formação continuada do profissional do ensino de Ciências diante de mudanças continuas nas estruturas curriculares da educação nacional. A partir dos resultados, os estagiários poderão iniciar o desenvolvimento de uma visão crítica da realidade da educação básica e reflexão sobre suas futuras práticas docente, pois a observação é vista como metodologia que possibilita um conhecimento mais próximo sobre o processo de ensino aprendizagem. O Estágio Supervisionado permite a integração da teoria e da prática; do conceitual com o concreto, do virtual com o real. É, portanto, o Estágio, uma importante parte integradora do currículo, a parte em que o licenciando vai assumir pela primeira vez a sua identidade profissional e iniciar o compromisso com o aluno, com sua família, sua comunidade, com a instituição escolar e com o sentido de profissionalismo que implique na busca de um ensino significativo.
\end{abstract}

Palavras-chave: Estágio supervisionado; Ensino de Ciências Naturais; Formação discente.

\section{SUPERVISED PRACTICE CONTRIBUTIONS IN ACADEMIC EDUCATION}

\begin{abstract}
The paper is a research conducted by students of the Degree in Biological Sciences of the Federal University of Campina Grande - UFCG, during the course of the curricular component 'Supervised Practice I', in order to observe and analyze the importance of stage in the student/teacher training, through the analysis of methodological tools used by teachers, as well as possible learning resources used to teach the Natural Sciences contents. The observations and research were conducted in two public schools, located in the municipalities of São João do Rio do Peixe and Cajazeiras - Paraiba, in
\end{abstract}

\footnotetext{
${ }^{1}$ Universidade Federal de Campina Grande(UFCG), E-mail: danibiologia20@ gmail.com

${ }^{2}$ Universidade Federal de Campina Grande(UFCG), E-mail: edinardo.enc@gmail.com

${ }^{3}$ Universidade Federal de Campina Grande(UFCG), E-mail: jeffymarques@ gmail.com
} 
May 2016. The reflection of the action and pedagogical practice is an essential tool for continued professional training of Science education in the face of continuous changes in curriculum structures of national education as a whole. From the results, students begin to develop a critical view of the basic education reality and reflection on their future teaching practices because the observation is a methodology that enables a closer knowledge of the teaching and learning process. Supervised Practice enables the integration of theory and practice; the conceptual to the concrete, the virtual to real. Therefore, the Supervised Practice is an important integrated part of the curriculum, where the future educators will take the first time their professional identity and start the commitment to the student, their family, community, with the educational institution and the sense of professionalism involving competence for a meaningful learning.

Keywords: Supervised Practice; Natural Sciences teaching; Academic education.

\section{INTRODUÇÃO}

O Estágio Supervisionado é um cumprimento da Lei de Diretrizes e Bases da Educação Nacional (Lei Federal nº 9.394, de 20 de dezembro de 1996), que define que todo curso de Licenciatura deve oferecê-lo para a formação de professores que poderão atuar na rede de ensino pública ou privada de nosso país (BRASIL, 1998). Constitui um momento de construção e aprimoramento de conhecimentos e de habilidades essenciais ao exercício profissional, que tem como função integrar teoria e prática. Trata-se de uma experiência com dimensões formadora e sócio-política, que proporciona ao estudante a participação em situações reais de vida e de trabalho, consolida sua profissionalização e explora as competências básicas indispensáveis para uma formação profissional ética e corresponsável pelo desenvolvimento humano e pela melhoria da qualidade de vida.

Pode-se definir Estágio Supervisionado, portanto, como qualquer atividade que proporcione ao aluno adquirir experiência profissional específica e que contribua, de forma eficaz, para sua futura atuação docente. Insere-se nesse tipo de atividade as experiências de convivência em um ambiente de trabalho com cumprimento de tarefas com prazos estabelecidos, trabalho em um ambiente hierarquizado e com componentes cooperativistas ou corporativistas, etc. O objetivo é fornecer ao estudante a oportunidade de aplicar seus conhecimentos acadêmicos em situações da prática profissional clássica, criando a possibilidade do exercício de suas habilidades. Espera-se que, com isso, que o aluno tenha a opção de incorporar atitudes práticas e adquirir uma visão crítica de sua área de atuação profissional (OLIVEIRA e CUNHA, 2006).

RPI Revista de Pesquisa Interdisciplinar, Cajazeiras, v. 1, Ed. Especial, 212 - 221, set/dez. de 2016. 
Nesta direção, o Estágio Supervisionado constitui um momento de construção e aprimoramento de conhecimentos e de habilidades essenciais ao exercício profissional, que tem como função integrar teoria e prática. Trata-se de uma experiência com dimensões formadora e sócio-política, que proporciona ao estudante a participação em situações reais de vida e de trabalho, consolida a sua profissionalização e explora as competências básicas indispensáveis para uma formação profissional ética e corresponsável pelo desenvolvimento humano e pela melhoria da qualidade de vida (BARREIRO, 2006).

Assim sendo, o estágio, nos cursos de formação de professores, possibilita que os futuros docentes compreendam a complexidade das práticas institucionais e das ações aí praticadas por seus profissionais como alternativa no preparo para inserção profissional, visto que é entendido como peça fundamental na construção da identidade do agente educador (PIMENTA e LIMA, 2012). Segundo Oliveira e Cunha (2006), o Estágio Supervisionado é um exercício que fornece ao aluno obter a experiência profissional que é relativamente significativo para a sua inserção no mercado de trabalho. É uma atividade obrigatória que deve ser efetuada pelos estudantes de cursos de Licenciatura e deve cumprir uma carga horária pré-estabelecida pela instituição de Ensino, essa relação entre teoria e prática é indispensável no processo de ensino aprendizagem.

A passagem dos estagiários pela escola constitui-se um fenômeno de influências recíprocas, onde tanto os estagiários quanto os demais sujeitos envolvidos no contexto da instituição aprendem e ensinam sobre a profissão docente, bem como podem construir saberes decorrentes desse processo perceptivo (LIMA, 2012). Com isso, o estágio é o espaço/tempo no currículo de formação destinado às atividades que devem ser executadas pelos licenciados nos futuros campos de atuação profissional, onde os estudantes devem tentar fazer a leitura da realidade, o que exige competências para saber observar, descrever, registrar, interpretar e problematizar e, consequentemente, propor alternativas de intervenção (PIMENTA, 1995). A observação dos componentes que compõem o agregado escolar - professor, aluno, escola, direção - permitirá um planejamento sobre a realidade observada e atuação na escola, com vista a uma melhor adequação às práticas e ações desenvolvidas pelo profissional docente, assim como a investigação detalhado do Plano Político Pedagógico (PPP) permitirá uma melhor avaliação da estrutura político pedagógica e uma melhor orientação para as atividades do estágio supervisionado (BARREIRO, 2006).

Para Pimenta e Lima (2012), o exercício de qualquer profissão é técnico também, pois precisa utilizar técnicas para sua execução; nesse caso, também a profissão professor RPI Revista de Pesquisa Interdisciplinar, Cajazeiras, v. 1, Ed. Especial, 212 - 221, set/dez. de 2016. 
desenvolve habilidades específicas para realizar tal atividade. Todavia, as habilidades não são suficientes para a solução dos problemas com os quais se defrontam, dado que a redução das técnicas não dá conta do conhecimento científico e nem da complexidade das situações do exercício desses docentes. O professor precisa saber desenvolver habilidades que condizem com a prática, conforme as diversas situações em que ocorre ensino, ou seja, traçar objetivos do que se pretende alcançar com determinada técnica, articulando teoria, prática e habilidades desenvolvidas. Diante disso, o docente precisa ter conhecimento científico, prático e técnico.

Desse modo, a efetividade na construção do conhecimento científico e tecnológico se dá de modo efetivo através do direcionamento das práticas e ações pedagógicas das representações sociais, que é incorporado como cultura. $\mathrm{O}$ direcionamento da ação docente caracteriza-se pelo entendimento do processo de produção do conhecimento como atividade humana, que é historicamente moldada por fatores internos e externos da cultura que precisa ainda ser compreendida de forma mais abrangente (DELIZOICOV et al., 2002).

O ensino de Ciências Naturais, ao longo de sua curta história na escola fundamental, tem se orientado por diferentes tendências que ainda hoje se expressam na sala de aula. Assim, ressalta-se a importância do professor de Ciências e de sua formação, pois é a partir da formação humana e científica do discente que novas propostas e possibilidades podem ser incorporadas a vivencia na sala de aula sem tirar dele o pensar, o criticar, o refletir da própria ação, como meio de ação, como agente criador e formador (PRADO, 1998). Para o ensino de Ciências Naturais é necessária a construção de uma estrutura geral da área que favoreça a aprendizagem significativa do conhecimento historicamente acumulado e a formação de uma concepção de Ciência, suas relações com a Tecnologia e com a Sociedade. Portanto, é necessário considerar as estruturas de conhecimento envolvidas no processo de ensino aprendizagem - do aluno, do professor, da Ciência (BRASIL, 1998).

Segundo Pimenta e Lima (2012), o exercício da docência é que define qual objetivo o profissional deseja alcançar e a relação do estagiário com a realidade escolar norteará suas ações contribuindo para o desenvolvimento e aprimoramento do futuro professor, pois é a partir das observações que se verifica a discrepância entre teoria e prática e esta percepção é resultado de um olhar crítico da sala de aula como um todo, da relação aluno professor, assim como da relação Estado, Sociedade e Educação.

A partir da observação efetuada no âmbito escolar, deve-se pautar por uma visão investigativa da realidade, tanto pelo professor da Prática de Ensino quanto pelo futuro 
educador (BARREIRO, 2006). Diante dessa investigação é possível buscar formas de inovação, não se limitando apenas ao ensino tradicional, compreende-se a conveniência de sugerir uma formação dos professores como uma mudança didática (CARVALHO e GILPÉREZ, 2011).

Desse modo, as contribuições do estágio supervisionado nos cursos de formação de professores são inegáveis, pois além de promoverem um contato direto com o magistério, contribuem para uma inter-relação entre os componentes curriculares e a prática. No estágio podemos além de pôr em prática os ensinamentos que obtivemos no decorrer da graduação, podemos investigar novas formas de executar este conhecimento, a pesquisa é uma prática bastante eficaz para despertar um interesse por parte dos alunos, uma visão ampla da realidade, além de colaborar satisfatoriamente para seu aprendizado (MELLO e LINDNER, 2012).

Nessa perspectiva, o presente trabalho trata-se de uma pesquisa realizada por alunos do Curso de Licenciatura em Ciências Biológicas do Centro de Formação de Professores da Universidade Federal de Campina Grande - CFP/UFCG, na disciplina Estágio Supervisionado, com o objetivo de observar e analisar o âmbito escolar como um todo e verificar as ferramentas metodológicas adotadas pelas professoras, além dos possíveis recursos pedagógicos utilizados para trabalhar os conteúdos de Ciências Naturais. A partir dos resultados, os estagiários poderão iniciar o desenvolvimento de uma visão crítica da realidade da educação básica e reflexão sobre suas futuras práticas docente, pois a observação é vista como metodologia que possibilita um conhecimento mais próximo sobre o processo de ensino aprendizagem.

\section{Desenvolvimento}

A pesquisa foi realizada em duas escolas da rede pública de ensino, sendo uma Estadual e outra Municipal, localizadas nos municípios de São João do Rio do Peixe e Cajazeiras, respectivamente, na Paraíba, em maio de 2016, com o intuito observar e analisar o âmbito escolar como um todo e verificar as metodologias adotadas possíveis recursos pedagógicos utilizados pelas professoras para lecionar os conteúdos de Ciências Naturais. Em ambas as escolas, o referido componente curricular é ministrado por docentes do sexo feminino. A coleta de dados se deu por meio de investigações observacionais durantes as RPI Revista de Pesquisa Interdisciplinar, Cajazeiras, v. 1, Ed. Especial, 212 - 221, set/dez. de 2016. 
aulas de Ciências em quatro turmas $\left(6^{\circ}, 7^{\circ}, 8^{\circ}\right.$ e $9^{\circ}$ ano) do Ensino Fundamental II de ambas as escolas e fichas de observações que foram respondidas pelos pesquisadores ao longo das aulas, onde foram analisados alguns pontos como a segurança das docentes na exposição dos conteúdos, os aspectos metodológicos utilizados, as relações interpessoais em sala de aula e as formas de avaliação utilizadas, permitindo alcançar o objetivo proposto.

Em conformidade com Ferreira et al. (2012), do ponto de vista da sua natureza, a pesquisa é do tipo aplicada. Quanto à forma de abordagem do problema, trata-se de uma pesquisa de caráter qualitativo. Quanto aos seus objetivos, a pesquisa é do tipo descritiva, visa descrever as características de determinada população ou fenômeno ou o estabelecimento de relações entre variáveis.

Após a coleta, os dados foram analisados e discutidos, sendo comparados com trabalhos feitos por outros autores.

De acordo com a metodologia descrita, foi analisado o aspecto escolar como um todo: a caracterização institucional do campo de estágio, o projeto político pedagógico (PPP), perfil pedagógico do espaço escolar e observações de atividades docentes em quatro turmas do Ensino Fundamental II. O uso de fichas previamente construídas com intuito de nortear as observações durante as aulas para coleta de dados foi relevante, visto que, a partir destas, pôde-se centrar nos objetivos da pesquisa.

Quando observado se as professoras apresentavam segurança na exposição dos conteúdos, verificou-se que as mesmas mostraram domínio do assunto, valendo-se de exemplos contextualizados e permitiam que os discentes fizessem questionamentos, proporcionando uma maior interação por parte destes. É relevante que os professores demonstrem habilidades de questionar e ilustrar suas aulas com exemplos e/ou analogias do cotidiano da realidade escolar. Rivas et al. (2005), aponta que é indispensável que o docente leve em consideração sua própria prática pedagógica para a construção do conhecimento.

Quando analisados os aspectos metodológicos utilizados durante as aulas, observou-se que os recursos metodológicos foram apenas quadro branco, pincel e o livro, dificultando a aprendizagem dos estudantes. Ataíde e Silva (2011), retratam que, no momento do planejamento, os professores devem traçar estratégias que despertem o interesse dos alunos com uso de recursos alternativos. E essa dificuldade de preparar aulas diversificadas pode estar relacionada à carência nos cursos de formação inicial ou falta de 
recursos nas escolas. No entanto, estes devem buscar estratégias alternativas como aulas de campo, vídeos, jogos didáticos, entre outros instrumentos.

Referente às relações interpessoais em sala de aula (professor(a)-aluno(a); aluno(a)-aluno(a); professor(a)-estagiário(a); aluno(a)-estagiário(a)), evidenciou-se uma relação de respeito das Professoras com os alunos e vice-versa, o que é relevante para a aprendizagem. A relação das docentes com os estagiários ocorreu de forma interpessoal. Todas as turmas de ambas as escolas tiveram uma ótima relação com os estagiários. Freschi e Freschi (2013), indicam que manter uma boa relação com os alunos é o primeiro passo para que as aulas se tornem proveitosas e agradáveis. É necessário haver um ambiente respeitoso e amistoso para facilitar o processo de ensino aprendizagem. $\mathrm{O}$ docente precisa ter amor e dedicação pela sua profissão, refletir sobre seu papel de educador e formador de cidadãos, estabelecendo assim boas relações interpessoais, pois, para ser um bom profissional não implica apenas em saber, dominar os conteúdos - precisa-se levar em consideração a importância do afeto e da formação de valores para o crescimento pessoal de ambos os envolvidos.

\section{Quando considerado o processo de avaliação realizado pelas docentes durante as} aulas, observou-se que foram usadas avaliações do tipo formativas ao longo do processo de ensino aprendizagem, onde as educadoras acompanhavam os estudantes ao longo do processo educativo e o conhecimento era formado ao longo das aulas, e do tipo somativa como forma de avaliar a aprendizagem dos alunos. Filho et al. (2012), retrata que anteriormente o processo avaliativo era visto apenas como forma de dar notas aos alunos e saber quem era aprovado ou reprovado; no entanto, sabe-se que essas práticas não são apenas para esse propósito, mas também para observar a aprendizagem dos alunos e se as metodologias utilizadas pelos professores estão sendo eficazes para a formação do conhecimento. O professor deve ter uma prática reflexiva, onde os alunos devem ser avaliados constantemente, onde o real sentido da avaliação é colaborar com a construção da aprendizagem.

Referente ao desenvolvimento geral das aulas observou-se que as duas turmas do $6^{\circ}$ ano de ambas as escolas eram muito barulhentas sendo apontada como as mais difíceis para ensinar. Contudo, apesar dos alunos serem desordenados e gostarem de conversar paralelamente, sempre realizavam as atividades propostas pela professora. Com relação às turmas do $7^{\circ}$ ano, as aulas foram bastante produtivas, pois as docentes desenvolveram atividades diversificadas e estimularam a participação dos alunos na leitura. Os estudantes, apesar de serem agitados e gostarem de conversar durante as aulas, sempre realizam as RPI Revista de Pesquisa Interdisciplinar, Cajazeiras, v. 1, Ed. Especial, 212 - 221, set/dez. de 2016. 
atividades de leituras que eram solicitadas. Nas turmas do $8^{\circ} 9^{\circ}$ anos, a maioria dos alunos se mostrava interessados pelos conteúdos de Ciências, apresentavam um bom comportamento e isso contribui muito para a formação de conhecimentos. Em todas as turmas observou-se a falta de recursos inovadores por parte das docentes, sendo um dos grandes desafios a ser enfrentado na formação de professores.

\section{Conclusão}

Este trabalho foi desenvolvido a partir de observações realizadas nas aulas de Ciências Naturais durante o curso do componente curricular Estágio Supervisionado I. A realização do estágio foi um momento em que a teoria e a prática se mesclaram para que fosse possível apresentar um bom resultado e, sobretudo perceber a necessidade em assumir uma postura não só crítica, mas também reflexiva da nossa prática educativa diante da realidade e a partir dela para que possamos buscar uma educação de qualidade e um aprendizado significativo.

O estágio supervisionado foi um momento de crescimento enquanto estudantes e futuros profissionais, onde esse período de experiência provocou uma nova concepção da realidade do ensino público brasileiro. Foi possível compreender que ser professor não significa apenas estudar um conteúdo, entrar na sala de aula e contar o que leu aos alunos $\mathrm{Na}$ realidade, o domínio do conteúdo é o mais simples de ser alcançado, pois depende somente do empenho do professor. Acredita-se que uma das formas que diferencia a qualidade do ensino é como e quão eficaz é a colocação dos conhecimentos adquiridos. Além disso, quais as suas estratégias para utilizar os recursos didáticos ou driblar a monotonia e dificuldades causadas pela provável falta destes recursos.

Os problemas de ensino e aprendizagem em Ciências têm uma forte ligação com as deficiências na formação dos professores marcada pela dificuldade em compreender a própria ciência e os processos educativos. Há uma valorização excessiva das teorias em detrimento das práticas, esquecendo-se da transposição didática, fator primordial no processo de aprender. Com isso observa-se que os desafios da escola atualmente vão além da sala de aula, além dos alunos, além do planejamento do professor, pois tudo isso depende da formação inicial e continuada do docente e essa formação irá refletir diretamente na metodologia aplicada no contexto social.

RPI Revista de Pesquisa Interdisciplinar, Cajazeiras, v. 1, Ed. Especial, 212 - 221, set/dez. de 2016. 
A formação continuada é importante, pois representa um quebra de paradigma e possibilita uma nova visão diante de uma formação tradicional e de saberes e práticas equivocadas, como se pode verificar país a fora. Essa superação é fundamental para o professor que necessita ter além do domínio de conceitos científicos, procedimentos, modelos e teorias exigidas como componente obrigatório nos parâmetros curriculares nacionais.

A reflexão da ação e prática pedagógica são instrumentos essenciais para a formação continuada do profissional do ensino de ciências diante de mudanças continuas nas estruturas curriculares da educação nacional como um todo, formas de inclusão social de contextualização e interdisciplinaridade são algumas considerações de algumas das propostas para uma educação democrática - para todos.

Sabe-se que temos um longo caminho a percorrer se quisermos alcançar uma educação de qualidade que possibilite uma melhoria no desenvolvimento de nosso país, mas não só no sentido de crescer a economia, pois acreditamos que uma educação de qualidade vai bem além, devendo privilegiar o desenvolvimento integral do ser humano.

Precisa-se ter uma postura efetiva de um profissional que se preocupa verdadeiramente com o aprendizado, que deve exercer o papel de um mediador entre a sociedade e a particularidade do educando. Devemos despertar no educando a consciência de que ele não está pronto, aguçando nele o desejo de se complementar, capacitá-lo ao exercício de uma consciência crítica de si mesmo, do outro e do mundo.

\section{REFERÊNCIAS}

ATAIDE, M. C. E. S.; SILVA, B. V. C. As metodologias de ensino de ciências: contribuições da experimentação e da história e filosofia da ciência. Revista HOLOS, Natal, v. 4, n. 27, p. 171-181, setembro. 2011.

BARREIRO, I. M. de F. Estágio Curricular na formação de Professores: Propostas e Possibilidades no Espaço Escolar In: __ . Prática de Ensino e Estágio Supervisionado na Formação de Professores. São Paulo: Avercamp, 2006. p. 87-115.

BRASIL, Lei No 9.394, de 20 de dezembro de 1996. Estabelece as diretrizes e bases da educação nacional. Disponível em:〈http://www.planalto.gov.br/ccivil_03/Leis/L9394.htm>. Acesso em: 16 de Novembro de 2015.

BRASIL. Secretaria de Educação Fundamental. Parâmetros Curriculares Nacionais: Ciências Naturais. Brasília: MEC/SEF, 1998. 138p. 
CARVALHO, A. M. P. de.; GIL-PÉREZ, D. Necessidades formativas do professor de Ciências. In: Formação de professores de Ciências: tendências e inovações. 10 ed. São Paulo: Cortez, 2011. p. 9-64.

DELIZOICOV, D.; ANGOTTI, J. A.; PERNAMBUCO, M. M. Desafios para o ensino de Ciências. In: Ensino de Ciências: Fundamentos e Métodos. São Paulo: Cortez, 2002. p. 31-42.

FERREIRA, L. B. et al. A técnica de observação em estudos de administração. In: Encontro da Associação Nacional de Pós-graduação e Pesquisas em Administração, 36, 2012, Rio de Janeiro - RJ. Anais... Rio de Janeiro: ANPAD, 2012. Online.

FILHO, J. A. da S. et al. Avaliação educacional: sua importância no processo de aprendizagem do aluno. In: Fórum Internacional de Pedagogia, 4, 2012, Parnaíba - PI. Anais... Parnaíba: REALIZE Editora, 2012. Online.

FRESCHI, E. M.; FRESCHI, M. Relações interpessoais: a construção do espaço Artesanal no ambiente escolar. Revista de Educação do Ideau, Alto Uruguai, v. 8, n. 18, p. 1-13, jul./dez. 2013.

LIMA, M. S. L. A escola como espaço de formação docente. In: aprendizagem da profissão docente. Brasília: Liber livro, 2012. p.85-120.

Estágio e

MELLO, S. P. T de.; LINDNER, L. M. T. A contribuição dos estágios na formação docente: observações de alunos e professores. In: Seminário de Pesquisa em Educação da Região Sul, 9, 2012, Caxias do Sul - RN. Anais... Caxias do Sul: UCS, 2012. Online.

OLIVEIRA, E da. S.G de.; CUNHA, V.L. O estágio Supervisionado na formação continuada docente à distância: desafios a vencer e Construção de novas subjetividades. Revista de Educación a Distancia, Ano V, n. 14, p.06-18, 2006.

PIMENTA, S. G. O Estágio na Formação de Professores: Unidade Entre Teoria e Prática? 4. ed. São Paulo: Cortez, 1995. 73p.

PIMENTA, S. G; LIMA, M. S. L. Estágio: diferentes concepções. In: Estágio e docência. 7. ed. São Paulo: Cortez, 2012. p.33-57.

PRADO, I. G. A. et al. Parâmetros curriculares nacionais, terceiro e quarto ciclos do ensino fundamental: Ciências Naturais. Brasília: Portal MEC, 1998.

RIVAS, N. P. P. et al. A (re) significação do trabalho docente no Espaço escolar: currículo e formação. In: Congresso estadual paulista sobre formação de educadores, 8, 2005, Águas de Lindóia - SP. Anais... Águas de Lindóia: UNESP, 2005. Online. 